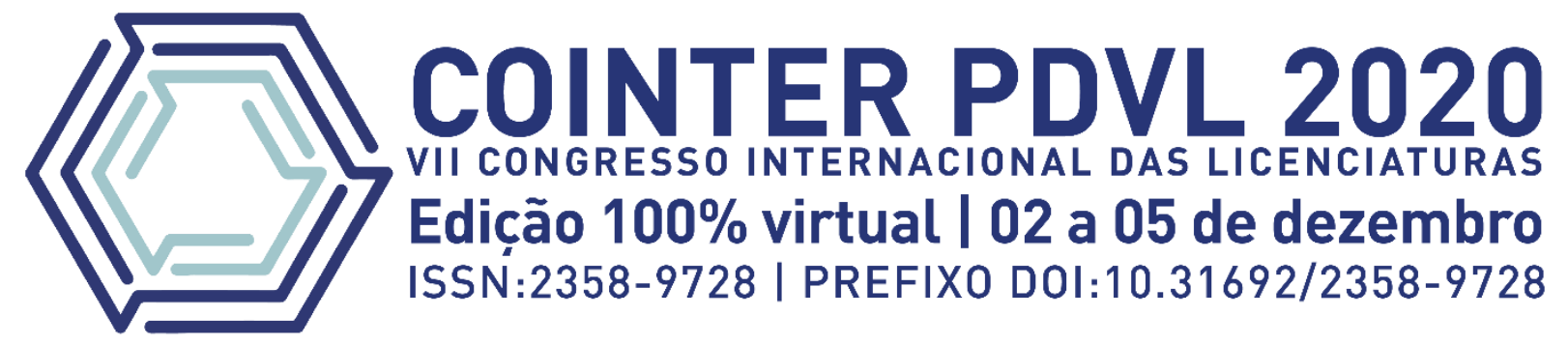

\title{
ENSINO REMOTO EM TEMPOS DE ISOLAMENTO SOCIAL: VISÃO DOS PAIS DOCENTES
}

\author{
ENSEÑANZA A DISTANCIA EN TIEMPOS DE AISLAMIENTO SOCIAL: \\ OPINIONES DE LOS PADRES MAESTROS
}

\section{REMOTE TEACHING IN TIMES OF SOCIAL ISOLATION: PERCEPTION OF PARENTS TEACHERS}

Apresentação: Comunicação Oral

Dan Vítor Vieira Braga ${ }^{1}$; Lauana Yngrid Ferreira Marins ${ }^{2}$

DOI: https://doi.org/10.31692/2358-9728.VIICOINTERPDVL.0424

\section{RESUMO}

Com a paralização das escolas pais, alunos e professores sejam capazes de implementar com sucesso um programa de ensino aprendizagem utilizando a nova modalidade de ensino a distância através das plataformas disponibilizadas na internet, dando continuidade da escolarização por meio de recursos tecnológicos. A importância desta pesquisa foi a possibilidade de analisar como o ensino domiciliar está sendo aplicado e comparar relatos de famílias para ajudá-las a desempenhar o auxílio educativo de forma satisfatória. $\mathrm{O}$ presente artigo pretende analisar o desempenho dos pais na prática docente no ensino remoto, ocasionado pela paralização das escolas devido à prevenção da disseminação da COVID-19 (doença respiratória viral pandêmica identificada em 2019, tendo como agente etiológico uma corona vírus). De modo secundário visa descrever a real consequência provocada pelo homeschooling nos pais e sua percepção acerca das vivências por eles protagonizadas nesta nova modalidade de educação; analisar a viabilidade prática da educação em casa protagonizada e mediada pelos responsáveis; analisar os limites e possibilidades de cada família neste recente cenário e como isso influenciou na experiência da educação em casa. A pesquisa foi desenvolvida por meio de um questionário on-line enviado via redes sociais para pais, ou para os responsáveis, de alunos matriculados na rede de ensino. As perguntas abordaram os possíveis desafios que a escolarização em casa e as consequências emocionais associadas a esta prática. Ficou explicito que o ensino domiciliar, na sua grande maioria, causou bastante insatisfação por parte dos pais. Além de seus afazeres cotidianos, os pais docentes tiveram de auxiliar os filhos nas atividades educacionais e complementar a didática escolhida pelos professores e escolas que geralmente envolveram o mau uso das ferramentas de ensino remoto e redes sociais. Os pais, forçadamente, se envolveram na dinâmica de ensino-aprendizagem sem a formação devida para isso. A utilização de novas propostas de ensino, teorizando de forma complementar os conteúdos das aulas, tem sido desafiador por infindas dificuldades operacionais, acabando por gerar em si alterações emocionais negativas ou potencializar as alterações desencadeadas pelo isolamento social. Em contrapartida, para uma pequena minoria dos participantes da pesquisa, o ensino domiciliar deveria ser regularizado. Isso aconteceu, quando as ferramentas educacionais para o ensino remoto foram bem utilizadas. Outro fator chave identificado foi que a boa condição financeira da família teve influência positiva na qualidade do ensino vivenciado em casa, os entrevistados deste grupo relataram mudanças significativas e ganhos de

\footnotetext{
${ }^{1}$ Docente, Fachusc, bragadvv@gmail.com

${ }^{2}$ Lic. em Ciências Biológicas, Fachusc, lau.yngrid28@hotmail.com
} 
ENSINO REMOTO EM TEMPOS DE ISOLAMENTO SOCIAL

aprendizagem nos filhos no sistema de homeschooling.

Palavras-Chave: COVID-19, Ensino Remoto, Homeschooling, docentes.

\section{RESUMEN}

Con la parálisis de las escuelas, padres, alumnos y docentes logran implementar con éxito un programa de enseñanza y aprendizaje utilizando la nueva modalidad de aprendizaje a distancia a través de las plataformas disponibles en internet, continuando la escolarización a través de recursos tecnológicos. Este artículo tiene como objetivo analizar el desempeño de los padres en la práctica docente en educación remota, provocado por la parálisis de las escuelas por la prevención de la propagación del COVID-19 (enfermedad respiratoria viral pandémica identificada en 2019, que tiene una especie de coronavirus como agente etiológico). En segundo lugar, pretende describir las consecuencias reales que provoca la educación en el hogar en los padres y su valoración de las experiencias vividas en este nuevo tipo de educación; analizar la viabilidad práctica de la educación a domicilio realizada y mediada por los responsables; analizar los límites y posibilidades de cada familia en este escenario reciente y cómo influyó en la experiencia de la educación en el hogar. La investigación se realizó mediante un cuestionario online enviado a través de las redes sociales a los padres o tutores de los alumnos matriculados en la red educativa. Las preguntas abordaron los posibles desafíos que presenta la escolarización en el hogar y las consecuencias emocionales asociadas a esta práctica. Se hizo explícito que la educación en el hogar, en su mayor parte, causó mucha insatisfacción por parte de los padres. Además de sus quehaceres diarios, los padres docentes debían ayudar a sus hijos en las actividades educativas y complementar la didáctica elegida por los profesores y las escuelas que generalmente implicaba el mal uso de las herramientas de enseñanza a distancia y las redes sociales. Los padres, a la fuerza, se involucran en la dinámica de enseñanza-aprendizaje sin la formación necesaria para ello. El uso de nuevas propuestas didácticas, teorizando de manera complementaria a los contenidos de las clases, ha sido desafiante debido a un sinfín de dificultades operativas, eventualmente generando cambios emocionales negativos en sí mismo o potenciando los cambios desencadenados por el aislamiento social. Otro factor clave identificado fue que la buena situación económica de la familia influyó positivamente en la calidad de la enseñanza en el hogar, los entrevistados de este grupo reportaron cambios significativos y avances en el aprendizaje de sus hijos en el sistema de educación en el hogar.

Palabras Clave: COVID-19, Educación a distancia, Educación en el hogar, profesores.

\section{ABSTRACT}

With the paralysis of schools, parents, students and teachers will be able to successfully implement a teaching and learning program using the new modality of distance learning through the platforms available on the internet, giving continuity to schooling through technological resources. This article aims to analyze the performance of parents in teaching practice in remote education, caused by the paralysis of schools due to the prevention of the spread of COVID-19 (pandemic viral respiratory disease identified in 2019, having a species of corona virus as its etiological agent). Secondly, it aims to describe the real consequence caused by homeschooling in parents and their appreciation for the experiences they experience in this new type of education; to analyze the practical feasibility of home education carried out and mediated by those responsible; analyze the limits and possibilities of each family in this recent scenario and how it influenced the experience of home education. The research was carried out by means of an online questionnaire sent via social networks to parents or guardians of students enrolled in the education network. The questions addressed the possible challenges that schooling at home and the emotional consequences associated with this practice. It was made explicit that home education, for the most part, caused a lot of dissatisfaction on the part of parents. In addition to their daily chores, teaching parents had to assist their children in educational activities and complement the didactics chosen by teachers and schools that generally involved the misuse of remote teaching tools and social networks. Parents, forcibly, became involved in the teaching-learning dynamics without the necessary 
training for that. The use of new teaching proposals, theorizing in a complementary way to the contents of the classes, has been challenging due to endless operational difficulties, eventually generating negative emotional changes in itself or potentiating the changes triggered by social isolation. On the other hand, for a small minority of research participants, home education should be regularized. This happened when the educational tools for remote teaching were well used. Another key factor identified was that the family's good financial condition had a positive influence on the quality of teaching at home, the interviewees of this group reported significant changes and learning gains in their children in the homeschooling system.

Keywords: COVID-19, Remote Education, Homeschooling, teachers.

\section{INTRODUÇÃO}

Em 1937, foram registrados os primeiros casos de um vírus que logo foi isolado, depois em 1965 o vírus foi denominado como corona vírus que não teve impacto na saúde pública. O Corona vírus (COVID) é uma doença causada por vários vírus de diferentes espécies gado, camelo, gato e morcegos, cujos principais sintomas são febres, tosse seca e cansaço (WU et al. 2020).

Em dezembro de 2019, infecções silenciosas e sintomas similares com o corona vírus, começaram a se espalhar rapidamente pelo mundo, sendo o contágio de pessoa para pessoa variando de assintomáticos a casos graves, levando inclusive ao óbito (BAUCHENER et al. 2020).

O aumento da quantidade de casos, a rápida ploriferação pandêmica e o rápido aumento dos óbitos gerou a necessidade de isolar as famílias numatentaiva de diminuir o contágio e o número de infectados. Com a promulgação de diversos instrumentos legais diversos países implementaram o isolamento social, onde nestas condições somente serviços essenciais e indispensáveis podem continuar a funcionar. As escolas por conterem uma quantidade alta de pessoas aglomeradas se tornando um ambiente de potencial elevado de disseminação da COVID-19, foram fechadas temporariamente (FARIAS, 2020).

Para manter a segurança da população e minimização da transmissão e da propagação do vírus, mitigando as perdas educacionais que seriam geradas com a paralização total das atividades escolares, uma das alternativas adotadas pelo governo brasileiro foi a adoção da modalidade do ensino remoto mediado por tecnologias da informação e comunicação. Neste modelo educacional os aplicativos e equipamentos tecnológicos ganham protagonismo nouniverso educacional (YUEN et al.2020).

As escolas das redes públicas e privadas em conjunto com os pais foram forçadamente obrigados a oferecem um ensino totalmente on-line com o acompanhamento e supervisão a distância dos professores. Assim, evitando aglomerações indesejadas e possibilitando que os 


\section{ENSINO REMOTO EM TEMPOS DE ISOLAMENTO SOCIAL}

alunos dessem continuidade no ano letivo. Foram adotadas umapluraridade de estratégias de ensino remoto com a disponibilização de videoaulas, explicações em áudio gravadas e o compartilhamento de atividades nas plataformas virtuais de aprendizagem. Foi preciso que os pais, também em isolamento social, estabelecessem uma nova rotina doméstica que incluissem as atividades educativas propostas para o desenvolvimento intelectual de seus filhos (DIAS et al. 2020).

Nem sempre se observa a materialização do cenário educacional e familiar ideal. $\mathrm{Na}$ maioria das vezes, a realidade é que os alunos possuem pais que não tem condições psicológicas para dar o suporte necessário. As famílias sem acesso à internet em suas residências ou sem aparelhos compatíveis. Os pais com índice mínimo de escolarização, ou pais que precisam sair para trabalhar diminuindo o tempo com os filhos. De forma que não conseguem conciliar seu tempo para o necessário auxílio nas atividades educacionais remotas (VIEIRA,2018).

O presente trabalho tem como objetivo descrever as estratégias das famílias em relação ao acompanhamento das atividades no ensino remoto, as consequências sobre a carga emocional dos "pais docentes" e o desafio destes no auxílio/acompanhamento dos filhos nas atividades educacionais durante o isolamento social devido a COVID-19.

\section{FUNDAMENTAÇÃO TEÓRICA}

O conhecimento é a capacidade humana de compreender, entender e apreender as coisas, cuturalmente fazendo a construção do saber por profissionais titulados como professores que tem a arte de formar seres com discernimento e capacidade de pensamento (MARASCHIN,1998).

Portanto contribuir para educação requer base e experiências no elemento construtivo de ensino, utilizando a dinamica pedagogica, economica, social, cultural de uma dada sociedade. Tutores responsaveis das crianças acreditam que qualquer pessoa pode educar e transferir conhecimento,utilizando de materiais e estudos em casa(DIAS et al. 2020).

O foco principal de algumas famílias é apresentar uma visão diferente da educação na construção do ensino famíliar, entender que há vários caminhos para uma educação de boa qualidade, transferir a responsabilidade total apara a escola prejudicando o aluno no seu desenvolvimento intelectual, estabelecendo que só no universo escolar se pode desenvolver habilidades cognitivas (HONORATO et al. 2020).

Porém, a realidade brasileira não nos permite esse cenario educativo, educacão domiciliar ou homeeschooling, como alternativa educacional é para poucos, a maioria dos 
brasileiros são analfabetos funcionais ou não possuem um ambiente adequado para tal escolha (FARIAS, 2020)

Segundo Fervorini (2009), outras causas das dificuldades dos pais em atividades de ensino remoto são que a maioria é pouco escolarizada e não conseguem acompanhar a dinâmica escolar e a nova tecnologia usada atualmente. Soma-se a isso ofato de não possuem internet disponível para realização dessas aulas.

Oliveira (2017) apura que as principais características do ensino secundário é a falta de informação no contexto familiar e a quase inexistência do diálogo constante entre a família e a escola impossibilita a eficácia de um modelo educativo remoto apropriado. $\mathrm{O}$ autor ainda destaca que muitos pais relatam que não é sua autêntica vocação ser referencial de ensino para seus filhos, com a justificativa de que a rotina diária impossibilita o protagonismo do processo educativo domiciliar. Estes conseguem apenas ser um apoio pedagógico em alguns raros momentos do ensino domiciliar.

Barboza e Knihs (2017) argumentam que a má qualidade da educação brasileira, a base do ensino de qualidade desvalorizada e professores sem a devida qualificação aumentam a violência moral, religiosa e filosófica na educação presencial, indicando que estar presente no ambiente escolar não significa educação e escolarização. Este contexto justifica a escolha de algumas famílias por realizar o ensino domiciliar. Para esses pais, o Ministério da Educação (MEC) é o principal responsável pela péssima qualidade do sistema educacional brasileiro, tendo em vista que $75 \%$ dos brasileiros entre 15 e 65 anos não conseguem ler e escrever de modo satisfatório, mesmo tendo frequentado a escola, passando para agraduação sem se quer compreender o que escrevem. Diante desses dados, muitas famílias buscam na justiça o direito de serem educadores primários dos seus filhos no acompanhamento e ensino totalmente em casa.

Por outro lado, Oliveira (2018) afirma que o papel do professor no processo de ensino/aprendizagem é de bastante importância e não pode ser excluído, pois, no mundo escolar, o professor deve atuar de forma que o aluno seja crítico a partir de outros conhecimentos e pensamentos na base do diálogo sempre voltado à pesquisa sócio político educacional, visando a educação do aluno inserida no convívio social.

Recentemente, este debate tem sido analisado como relevante para muitos pais que estão enfrentando o isolamento social devido a COVID-19. Um vírus aparentemente desconhecido que ocasionou impactos significativos na dinâmica global. Por não saber o que fazer, ou quem estava infectado, as autoridades estabelecem medidas radicais e consequentemente, determinaram o fechando das escolas para diminuir o contágio potencial e automaticamente, 


\section{ENSINO REMOTO EM TEMPOS DE ISOLAMENTO SOCIAL}

transferindo ensino no modelo presencial para o modelo totalmente on-line (BAI et al. 2020).

No município de Salgueiro, Sertão Central pernambucano, o Decreto Municipal nº 013, de 17 de março de 2020, declara situação de emergência em saúde pública no município e dispõe sobre medidas de enfrentamento da pandemia provocada pelo corona vírus (COVID-19) (SALGUEIRO, 2020). Devido ao advento deste instrumento legal, as redes públicas e privadas de educação tiveram que se adequar as determinações legais e iniciaram o planejamento e posterior execução das atividades educacionais adotando modelo de educação.

\section{METODOLOGIA}

O presente estudo realizado no munincipio de Salgueiro, Sertão Central do estado de Pernambuco, Brasil (Figura 1). O muninipio de Salgueiro possui uma extensão territorial de $1678,564 \mathrm{~km}^{2}$ e localiza-se a 520km da capital estadual, Recife (IBGE, 2017).

Figura 1: Mapa de localização do município de Salgueiro.

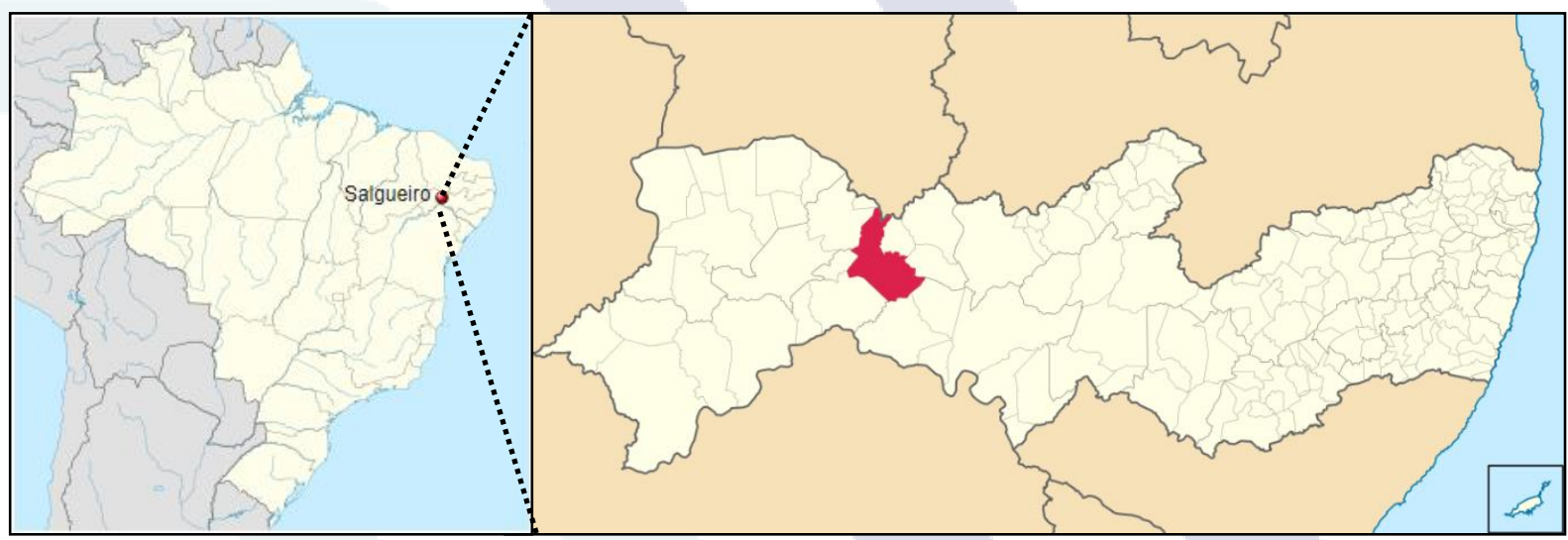

Fonte: Modificado de Wikipedia (2018).

Conforme os dados do último senso geográfico do IBGE (2010), a taxa de escolaridade de 6 a 14 anos de idade no município é de 96,7\%. Salgueiro atingiu 5,3 de nota do Ideb anos iniciais do ensino fundamental e 4,6 nos anos finais do ensino fundamental, ambas referente à rede pública de ensino. Estes dados colocam o município como o melhor em sua microrregião em Pernambuco (IDEB, 2017a e 2017b).

A coleta de dados foi realizada no período de agosto a outubro de 2020 , tem natureza qualitativa com o processo de investigação por meio da pesquisa sendo executada através de um questionário on-line desenvilvido com o uso do aplicativo "Google Formulário", com a distribuição do link, https://forms.gle/oDYEnDV1eqMYwQSU9, que serviu para construção do embasamento teórico. O questionário consistia de 25 perguntas formuladas com o foco na 
caracterização das famílias; das condições operacionais da educação remota; da analia do ensino e apoio prestado pelas escolas aos pais, bem como da valiação dorendimento escolar durante as atividades remotas. Por fim, buscou-se caracterizar o impacto deste novo modelo educacional no estado emocional e na saúde dos pais. O link para convite departicipação na pesquisa foi enviado às famílias pelas redes sociais, principalmente nos grupos de pais no aplicativo WhatsApp. O questionário foi direcionado para famílias com filhos matriculados na rede de ensino e que se encontram em municípios comatividades educacionais suspensas devido aà Covid 19, seja integrante da rede particular ou pública e de todos as fases escolares (pré-escola; ensino fundamental e ensino médio).

\section{RESULTADOS E DISCUSSÃO}

Educação é um assunto que reflete nas prioridades da sociedade, assim o processo de aprendizagem também pode ser feito fora da escola. Atualmente, para conter a propagação do novo coronavírus, o ensino domiciliar é uma modalidade em que pais ou tutores responsáveis das crianças assumem o papel de professores dos filhos, garantindo a continuidade dos estudos em casa. O trabalho apurou informações com os responsáveis de ensinar em casa, e por meio da pesquisa procourou compreender os principais desafios enfrentados pela família.

Houve o retorno de 65 informantes à solicitação de participação na pesquisa, o que permitiu analisar um universo amostral de de 94 crianças. Todos os entrevistados têm seus filhos matriculados na rede de ensino com maioria na rede pública (65.6\%), distrubuídos nas séries do, pré-escola, infantil, ensino fundamental, médio e superior. A maioria dos entrevistados $(97 \%)$.continuaram com as atividades em casa mesmo relatando as dificuldades vivenciadas no ensino remoto.

Mais da metade dos informantes (76,9\%) relataram ter facilidade em utilizar os aplicativos disponíveis na internet para aulas. Apenas $(6,2 \%)$ reconheceram não ter dominío, nem sabem utilizar os meios tecnológicos utilizados nas aulas e isso é preocupante pois acabam por não poderem mediar as atividades educacionais remotas (figura 2). 


\section{ENSINO REMOTO EM TEMPOS DE ISOLAMENTO SOCIAL}

Figura 2: Autoavaliação dos pais, ou responsáveis, acerca do seu domínio com relação ao uso dos aplicativos e equipamentos necessários à realização das aulas.

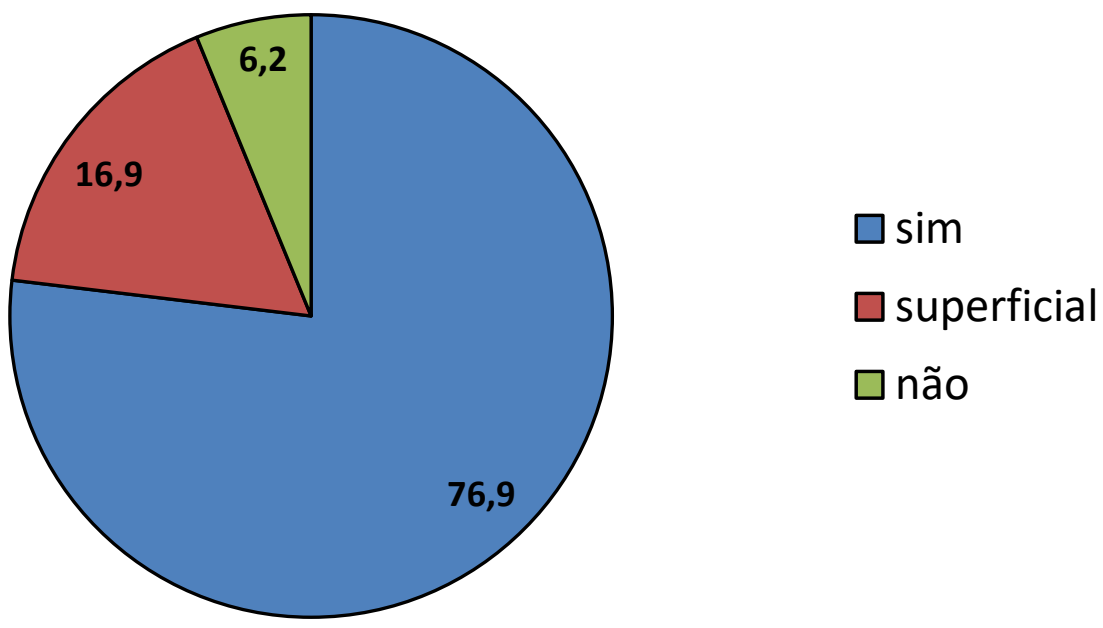

Fonte: Própria (2020).

Corroborando com Oliveira 2017, quando ele afirma que a falta de planejamento dos pais na dificuldade do ensino, atrapalhando o desenvolvimento das crianças ainda é o principal desafio, pais não estabelecem uma rotina diária de acompanhar o ensino remoto, relatam que a falta de paciência, concentração, ter disciplina, internet, tempo, o trabalho, dificuldades no repasse das matérias atrapalhando no desenvolvimento das atividades é o maior obstáculo do ensino remoto.

As duas estratégias de ensino remoto que prodominaram foram as videoaulas $(52,4 \%)$, seguidas do envio de vídeos curtos explicando o conteúdo (17,5\%). No geral, houve uma grande diversidade de ferramentas utilizadas pelas escolas nesta modalidade de homeschooling, os pais relataram 12 diferentes estratégias de ensino. Porém, houve predomínio de apenas três estratégias de ensino e as demais apresentaram apenas uma ocorrência dentre os 65 informantes (Figura 3).

Alguma dessas estratégias adotadas se destaca e seu uso isolado gera dúvidas na sua eficácie como instrumento de aprendizagem sem acompanhamento dos professores. Nesta situação, estão o envio de áudios curtos pelo aplicativo WhattsApp e a entrega de blocos de atividades impressas sem estar associado a explicação prévia do conteúdo. Alguns pais relataram que acabam por ter de complementar as estratégias de ensino remoto executadas pelas escolas, apesar de não terem formação de educadores. 
Figura 3: Frequência relativa das diferentes estratégias de ensino remoto adotadas pelas escolas durante o isolamento social devido à COVID-19.

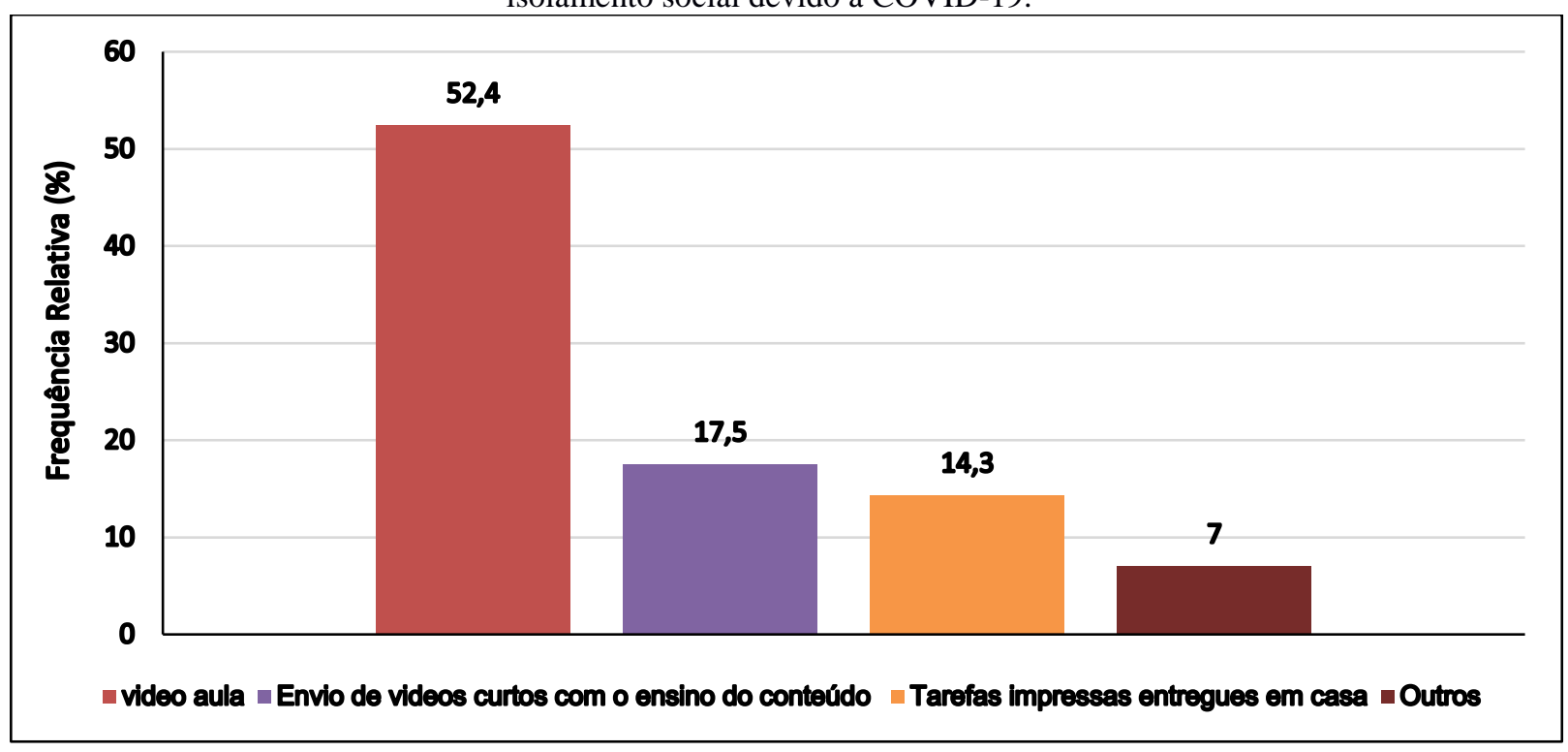

Fonte: Própria (2020).

As escolas disponibilizaram aplicativos para facilitar o acesso às aulas como o Google Meet, Plurall, Zoom, Whatsapp, Google Classeroom e Youtube. Os pais utilizam os meios tecnológicos para facilitar a comunicação com o professor na hora das aulas, variando o acesso e tempo dessas aulas de trinta minutos à duas horas de três a cinco dias na semana, independentemente da disponibilidade da família de dar suporte ao ensino remoto.

Segundo Mendes et al (2020), o ensino remoto consiste na adaptação das ferramentas tecnológicas diante do cenário de isolamento. As adaptações das atividades para o uso das aulas, sendo os encontros nas plataformas digitais utilizados para manter o contato professor e aluno, sem desfazer o vínculo com a escola e garantir que a educação se encaixe na rotina familiar. Isso explica a maior frequência observadas para o uso das videoaulas.

Um depoimento de uma mãe que realiza educação domiciliar diz:

"Aqui em casa está sendo uma maravilha o ensino domiciliar. Sempre fiz minha faculdade para praticar a homeschooling, agora com a pandemia foi como se fosse um estagio para nós. Sempre praticamos o ensino, a escola é só uma extensão. Está sendo maravilhoso. Não nos sentimos professores delas, nos sentimos pais educadores. Nosso papel né”.

Porém este depoimento retrata o sentimento da minoria dos pais que participaram da pesquisa. Segundo Barboza e Knihs (2017), a melhor educação e construção de conhecimento é criada em casa pelos pais. Um meio alternativo pelos pais que insatisfeitos com o ensino e aprendizado dos seus filhos, lutam na justiça pelo direito de regularização, justificando um maior rendimento por parte do filho no ensino em casa, considerando a importância do papel 


\section{ENSINO REMOTO EM TEMPOS DE ISOLAMENTO SOCIAL}

da família na formação da criança. Porém, na prática as atividades domésticas cotidianas somadas as relacionadas ao homeoffice durante o isolamento social, aumentaram a carga física e emocional sobre os pais, dificultando uma percepçãopositiva de mais uma responsabilidade sobre seus ombros.

Apesar da discussão do tema atual, para uma grande maioria dos educadores e estudantes ter acesso a materiais pedagógicos na internet para auxiliar nos estudos é desafiador. Múltiplas dificuldades foram relatadas pelos pais na entrevista, como uso limitado dos equipamentos e internet, não saber utilizá as plataformas de ensino on-line, ou não ter interesse em aprender acabam por limitar o aprendizado. Isto foram os maiores motivos do baixo rendimento dos alunos na educaçãoem casa. Embora apenas $(5,3 \%)$ dos entrevistados relataram não ter acesso à internet e a grande maioria $(46,9 \%)$ relatou que o seu acesso possui boa velocidade de conexão na maioria das vezes (Figura 4).

Figura 4: Avaliação da qualidade do acesso à internet utilizado para as atividades de ensino remoto durante a pandemia da COVID-19.

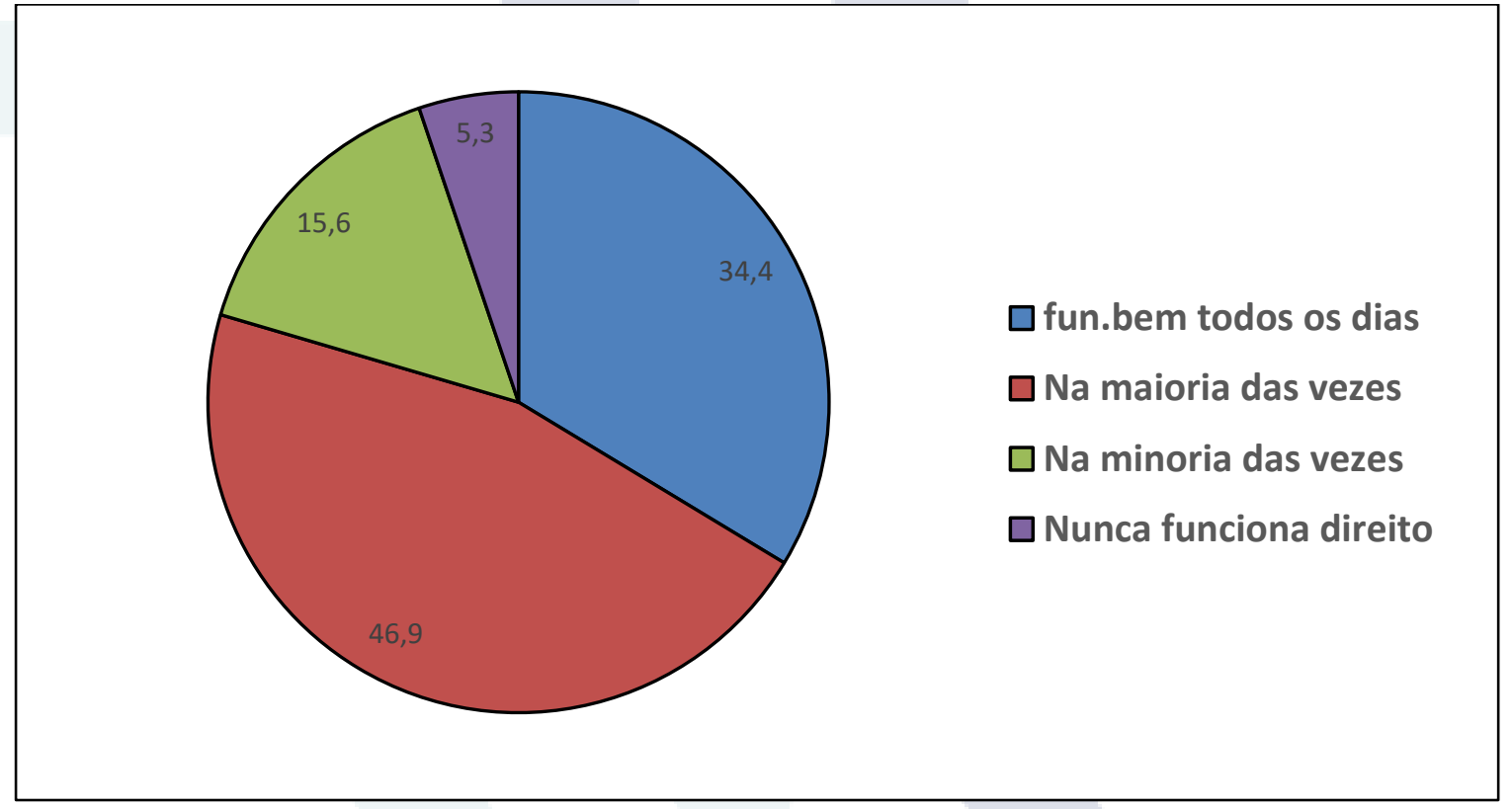

Fonte: Própria (2020).

Na opinião de Oliveira et al. (2015), ensinar não é tão fácil exige dedicação e inovação nas disciplinas repassadas, limitações de acesso a tecnologia pais pouco alfabetizados, desafiando o ambiente de ensino impossibilitando a capacidade dos pais de implementar um ensino aprendizagem de qualidade para seus filhos. O foco principal das escolas é compreender quais são as maiores dificuldades dos pais no ensino remoto e tentar ajudar os responsáveis no repasse. No entanto, os relatos demostram um ensino frustrado por inúmeras razões, como; interesse, compreensão das matérias, o tempo, disciplina, material didático, concentração, 
utilização da linguagem que impedem o desenvolvimento dos pais (Figura 5).

Figura 5: Frequência absoluta das diferentes dificuldades relatadas pelos pais durante o ensino remoto devido à COVID-19.

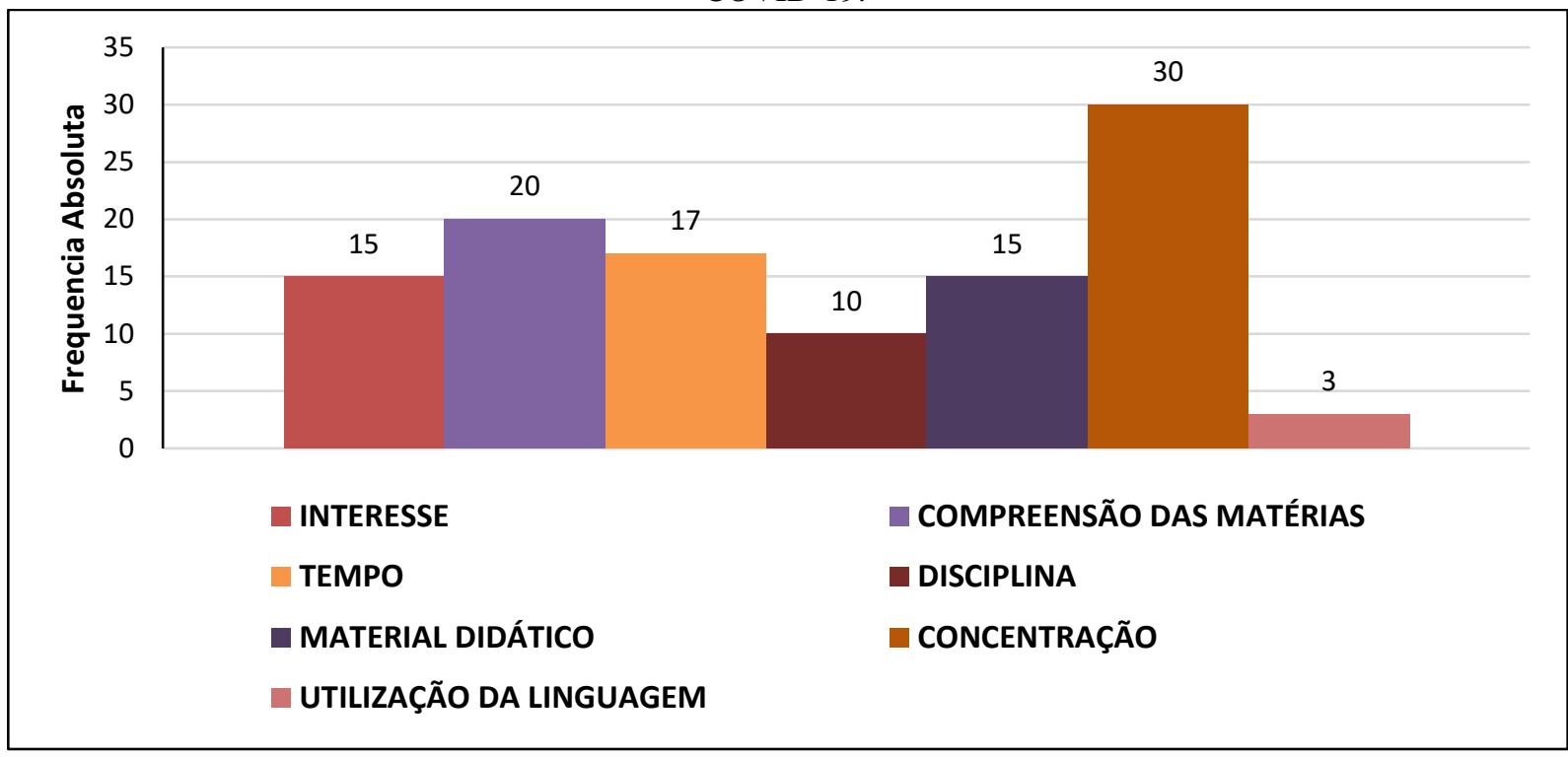

Fonte: Própria (2020).

Para Cazarin et al 2020, o processo aprendizagem depende muito da vontade e desejo próprio dos estudantes, não precisamos de muito para criar materiais pedagógicos com ferramentas simples que encontramos dispoiveis na natureza com criação própria. A maior preocupação dos professores é a falta de desejo por parte dos jovens de estudar desmotivando os pais no ensino em casa, pois sem um incentivo maior, contribuindo para que o aluno não consiga a concentração necessária a aprendizagem.

A exigência do isolamento social abalou a estabilidade emocional de todos, principalmente na área da educação, "pais professores" e alunos abalados psicologicamente, tentando se encaixar no novo perfil educacional no ensino online buscando o melhor do aprendizado e compreensão das aulas. Dentre as sensações experimentadas pelos pais ao ensinar seus filhos em casa durante o isolamento social, a tristeza pelo desempenho observado do filho, a preocupação e a falta de paciência foram as que predominaram (Figura 6). 


\section{ENSINO REMOTO EM TEMPOS DE ISOLAMENTO SOCIAL}

Figura 6: Frequência absoluta das diferentes sensações experimentadas pelos pais ao ensinar seus filhos em casa durante o ensino remoto devido à COVID-19.

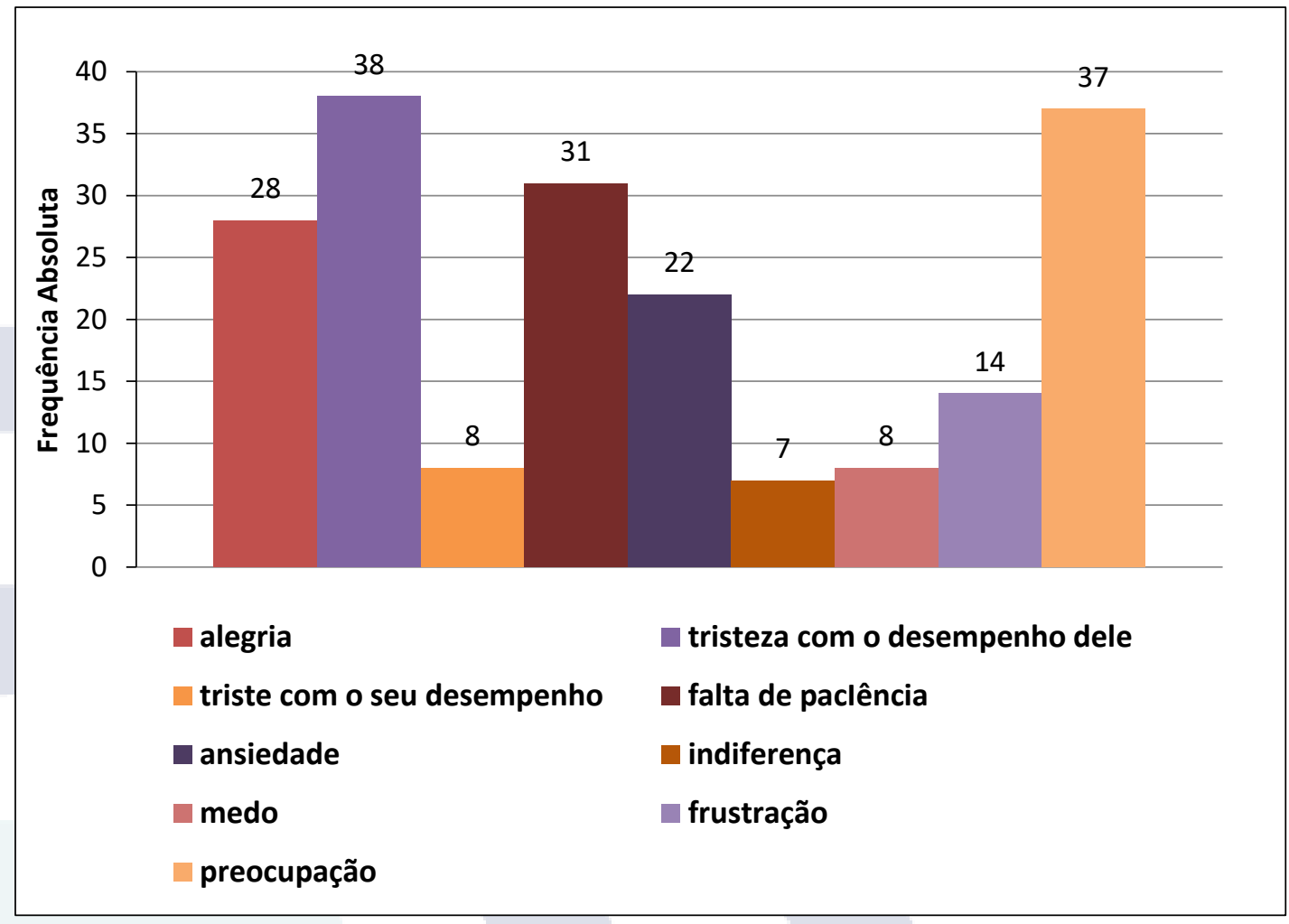

Fonte: Própria (2020).

O papel dos pais é manter o equilíbrio emocional, longe das escolas os pais podem criar estratégias de ensino para os filhos ocupando o tempo livre, criando laços familiares e o mais importante tronando-se referência para (FERREIRA et al. 2013). Porém, 27\% dos pais relataram experimentar alterações de saúde devido ao estresse associado ao homeschooling. Dentre as alterações relataram destacaram-se cefaleia, dores musculares e falta de ar.

Ao serem estimulados a avaliar a eficácia da aprendizagemde seus filhos o ensino remoto devido à COVID-19, a grande maioria avaliou como regular $(57,8 \%)$ e péssima $(18,8 \%)$. De acordo com os resultados coletados, grande parte das escolas utiliza os meios tecnológicos necessárioa à aprendizagem, mas não criaram estratégias para melhorar o ensino em casa (Figura 7). 
Figura 7: Avaliação da aprendizagem dos filhos conforme a percepçãodospais durante o ensino remoto devido à COVID-19.

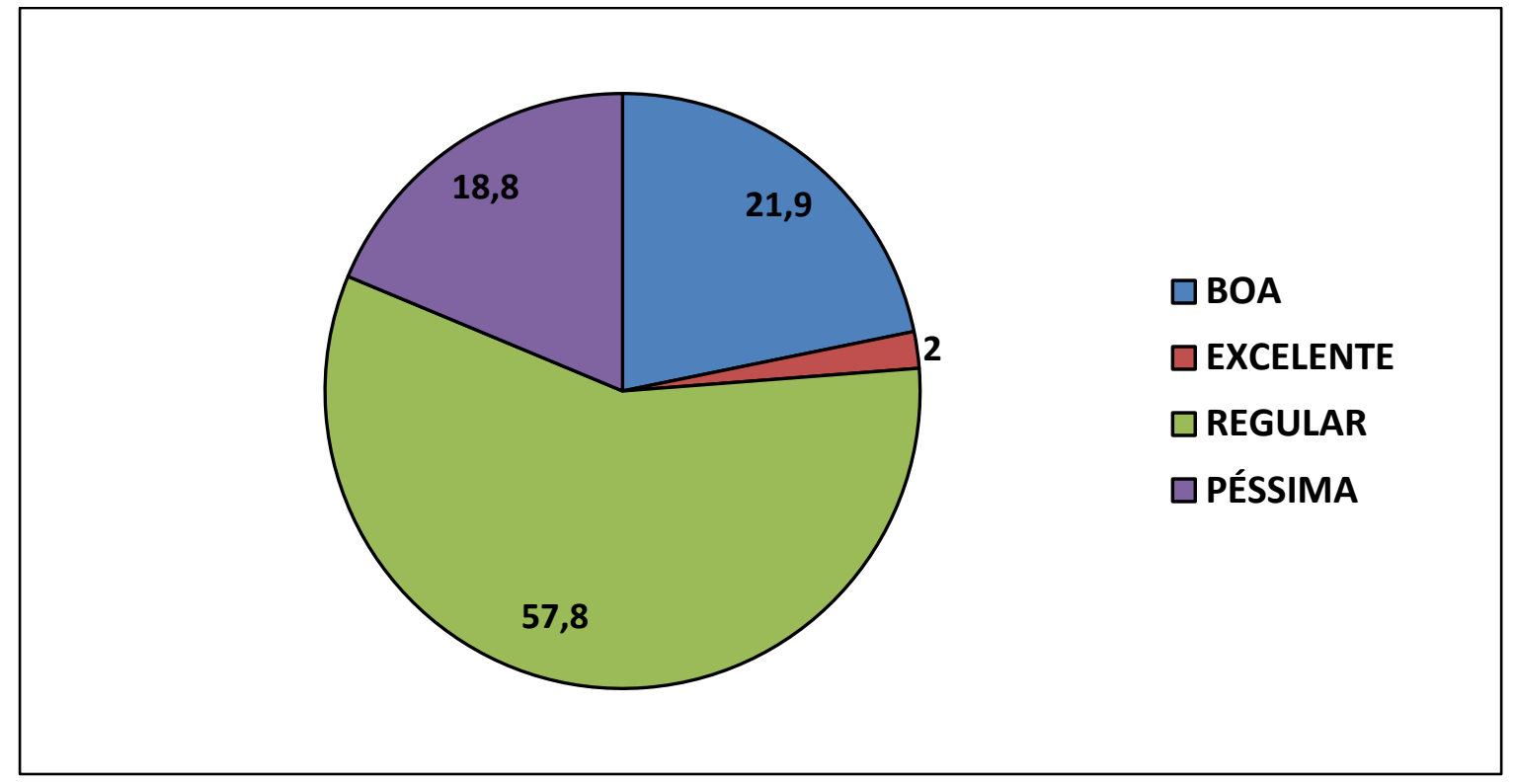

Fonte: Própria (2020).

Os pais que usualmente não dispõem de vocação, tempo, paciência e criatividade para à educação, não tiveram suporte de modo eficiente dos projetos pedagógicos das escolas para diminuir o medo, a ansiedade, a tristeza, a frustração, a raiva e a angustia de enfrentarem os desafios diários da educação, estando isolados em suas residências. Em contrapartida, para os filhos os pais pilares de referencia que foram abalados e para as crianças educar sempre será um ato de amor, um papel fundamental na vida dos pais e responsáveis, sendo a escola apenas uma extensão de tudo isso.

\section{CONCLUSÕES}

Este trabalho possibilitou entender como os pais, agora também na condição de professores, conseguiram externalizar suas dificuldades e frustações durante o ensino remoto. Além de explicitar o quanto o estado psicológico e a saúde dos pais foram abaladas nesse período. Por fim, o baixo nível de aprendizagem reconhecidamente fruto do modelo adotado de homeschooling é um fator a ser destacado na pesquisa e considerado pelas escolas para definir estratégias de mitigação das perdas de aprendizagem reconhecidamente ocorridas durante o ensino remoto vivenciado em 2020. 
ENSINO REMOTO EM TEMPOS DE ISOLAMENTO SOCIAL

\section{REFERÊNCIAS}

BAI Y, YAO L, WEIT, TIAN F, JIN DY, CHEN L, WANGM. Presumed asymptomatic cannier transmission of covid-19. Jama. 2020

BARBOZA, Q. M.; KNIHS, K. O direito á educação domiciliar e os novos desafios ao supremo tribunal federal: recurso extraordinário $888.815 / \mathrm{RS}$, Lacuna legislativa e direito comprado. Paraná, Universidade Positivo online-Polo Araucária,2017.

BAUCHNER, H.; SHARFSTEIN, J. Medical students, national servises, and public health. A bold response to the covid-19 pandemic. Jama Journal of medical. April;2020

EPIDEMIOLOGY WORKINK GROUP FOR NCIP EPIDEMIC RESPONSE CCFDCAP. The epidemiological characterististics of an outbreak of 2019 novel coronavirus diseases (COVID19) in China. Chinese Journal of Epidemiology. 2020, n.41, p.145-151.

FARIAS, S. O avanço da covid-19 e o isolamento social como estratégia para redução da vulnerabilidade. Espaço e economia, Rio de Janeiro, v.17.n2p 1-12, abril.2020.

FERREIRA, D., SANTOS, A. J., RIBEIRO, O., FREITAS, M., CORREIA, J.; RUBIN, K. Isolamento social e sentimento de solidão em jovens adolescentes. Análise Psicológica, Lisboa, v. 31, n. 2, p. 117-127, jun. 2013.

HONORATO, G.; MARCELINO B. A arte de ensinar e a pandemia covid-19: visão dos professores. Revista diálogos em educação, Rio de Janeiro, v.1, n.1, 2020. p. 208-220

INSTITUTO BRASILEIRO DE GEOGRAFIA E ESTATÍSTICA. Dados do mapa. SalgueiroPernambuco,2017.

IDEB - Anos iniciais do ensino fundamental (Rede pública): Ministério da Educação, Instituto Nacional de Estudos e Pesquisas Educacionais - INEP - Censo Educacional 2017.

IDEB - Anos finais do ensino fundamental (Rede pública): Ministério da Educação, Instituto Nacional de Estudos e Pesquisas Educacionais - INEP - Censo Educacional 2017.

MARASCHIN,Cleci,AXT,Margarete.Conhecimento. In:STREY, Marlene Nevs et aalli. Psicologia social contemporânea: livro texto, Petrópolis, Rio de Janeiro:1998 p.133-145.

OLIVEIRA. W. MENDES, T. Uma abordagem sobre o papel do professor no processo ensino/aprendizagem. São Paulo, universidade Federal de São Carlos,2018.

SALGUEIRO. Decreto Municipal no 013, de 17 de março de 2020. Define medidas temporárias adicionais para enfrentamento da emergência de saúde pública decorrente do nono corona vírus e das outras providências, Salgueiro, 2020.

VIEIRA, M. Desafios de pais educadores no século XXI: como educar. Revista Científica da Faculdade Sete de Setembro. V.12, n. 20, p.38-49. Paulo Afonso, BA: FASETE, 2018. 2018.

YUEN, K.S.; YE, Z.W.; FUNG, S.Y; SARS-CoV-2 and COVID-19: The most important 
BRAGA, et al.

research questions. Cell Biosci. n.10, 40 (2020). https://doi.org/10.1186/s13578-020-00404-4. 